\title{
PRONAF AGROECOLOGIA: REFLEXÕES SOBRE O (NÃO) ACESSOAO SUBPROGRAMA NO TERRITÓRIO DA CIDADANIA CANTUQUIRIGUAÇU/PR
}

PRONAF Agroecologia: reflections on the (no) acess to the subprogram in the territory of citizenship Cantuquirigaçu/PR

Doi: 10.48075/igepec.v25i1.23900

Grasieli de Fátima Rode

Janete Stoffel

Anelise Graciele Rambo 


\title{
PRONAF AGROECOLOGIA: REFLEXÕES SOBRE O (NÃO) ACESSO AO SUBPROGRAMA NO TERRITÓRIO DA CIDADANIA CANTUQUIRIGUAÇU/PR
}

\author{
PRONAF agroecologia: reflections on the (no) access to the subprogram in the \\ territory of citizenship Cantuquiriguaçu/PR
}

Doi: 10.48075/igepec.v25i1.23900

Grasieli de Fátima Rode Janete Stoffel Anelise Graciele Rambo

\begin{abstract}
Resumo: Este estudo buscou analisar em que medida o Pronaf vem estimulando a produção agroecológica na agricultura familiar, em municípios do Território da Cidadania Cantuquiriguaçu, com ênfase no subprograma Pronaf Agroecologia. No desenvolvimento da pesquisa procurou-se compreender limitações e potencialidades do acesso ao crédito para a produção orgânica/agroecológica. Os recursos metodológicos utilizados foram pesquisa bibliográfica e levantamento de dados secundários e primários. A pesquisa bibliográfica e os dados secundários confirmam baixo acesso ao Pronaf como programa e inexistência de acesso ao subprograma denominado Agroecologia. Quanto aos dados primários, foram efetuadas entrevistas com 31 agricultores familiares que atuam na produção orgânica/agroecológica. Nesta etapa os resultados apontam que há necessidade de recursos financeiros para desenvolver a produção orgânica/agroecológica, entretanto as possibilidades de acesso ao Pronaf, como política pública, estão muito distantes da realidade dos agricultores familiares pesquisados.
\end{abstract}

Palavras-chave: Desenvolvimento Regional; Crédito Rural; Orgânicos; Agroecologia.

Abstract: This study sought to analyze the extent to which Pronaf has been stimulating agroecological production in family farming in municipalities in the Territory of Citizenship Cantuquiriguaçu, with emphasis on the subprogram Pronaf Agroecology. In developing the research, we sought to understand the limitations and potential of access to credit for organic / agroecological production. The methodological resources used were bibliographic research and survey of secondary and primary data. Bibliographic research and secondary data confirm low access to Pronaf as a program and lack of access to the subprogram called Agroecology. As for primary data, interviews were conducted with 31 family farmers who work in organic / agroecological production. At this stage, the results indicate that there is a need for financial resources to develop organic / agroecological production, however the possibilities of access to Pronaf, as a public policy, are very distant from the reality of the researched family farmers.

Key-words: Regional Development; Rural Credit; Organic; Agroecology.

Resumen: Este estudio buscó analizar en qué medida Pronaf ha estado estimulando la producción agroecológica en la agricultura familiar en los municipios del Territorio de Ciudadanía Cantuquiriguaçu, con énfasis en el subprograma Pronaf Agroecology. Al desarrollar la investigación, buscamos comprender las limitaciones y el potencial del acceso al crédito para la producción orgánica / agroecológica. Los recursos metodológicos utilizados fueron la investigación bibliográfica y la encuesta de datos secundarios y primarios. La investigación bibliográfica y los datos secundarios confirman el bajo acceso a Pronaf como programa y la falta de acceso al subprograma llamado Agroecología. En cuanto a los datos primarios, se realizaron entrevistas con 31 agricultores familiares que trabajan en la producción orgánica / agroecológica. En esta etapa, los resultados indican que se necesitan recursos financieros para desarrollar la producción orgánica / agroecológica, sin embargo, las posibilidades de acceso a Pronaf, como política pública, están muy alejadas de la realidad de los agricultores familiares investigados.

Palabras-clave Desarrollo Regional; Credito Rural; Orgánico; Agroecología. 
Informe GEPEC, ISSN: 1679-415X, Toledo, v. 25, n.1, p.10-26, jan./jun. 2021. 


\section{INTRODUÇÃO}

No Brasil, a agricultura familiar ocupa espaço de destaque, principalmente no que tange à sua pluralidade, capacidade produtiva, abastecimento interno, diversidade cultural, geração de trabalho e renda. Devido à importância desta categoria no país pelos motivos expostos, conhecer melhor sua realidade, de modo a contribuir para que as políticas públicas - a ela direcionadas - sejam aprimoradas, é tarefa do meio acadêmico.

Em termos de representatividade da agricultura familiar cabe destacar que os dados do IBGE (2020) apontam que no Brasil, do total de 4.996.287 estabelecimentos agropecuários existentes, 76,9\% são de agricultores familiares. No Estado do Paraná, dos 304.221 estabelecimentos agropecuários, os agricultores familiares detêm 75\% desta totalidade. Apesar desse setor ser numericamente mais significativo em relação aos estabelecimentos, a área ocupada é pequena. No país, conforme IBGE (2020), apenas $23 \%$ da área dos estabelecimentos agropecuários (em hectares) é de agricultores familiares, enquanto no Paraná este percentual é de 24,1\%.

A região do Território da Cidadania Cantuquiriguaçu é constituída por 20 municípios: Campo Bonito, Candói, Cantagalo, Catanduvas, Diamante do Sul, Espigão Alto do Iguaçu, Foz do Jordão, Goioxim, Guaraniaçu, Ibema, Laranjeiras do Sul, Marquinho, Nova Laranjeiras, Pinhão, Porto Barreiro, Quedas do Iguaçu, Reserva do Iguaçu, Rio Bonito do Iguaçu, Três Barras do Paraná e Virmond. Nestes há 24.765 estabelecimentos agropecuários, dos quais $78,7 \%$ são geridos por agricultores familiares que ocupam uma área de 304.456 hectares, o que corresponde a 28,4\% do total de área dos estabelecimentos agropecuários existentes na região (IBGE, 2020).

Apesar da representatividade da agricultura familiar no meio rural brasileiro, a inserção na agenda e a implementação de políticas públicas para a categoria é recente. Foi na década de 1990 que a categoria ganhou alguma expressividade e um delineamento, com a criação do Programa Nacional de Fortalecimento da Agricultura Familiar - Pronaf, no ano de 1995. O Programa surge com a finalidade de impulsionar o desenvolvimento sustentável do segmento rural, composto pelos agricultores familiares, através do acesso ao crédito (BRASIL, 2019). Dentre os subprogramas criados, aqui destacamos o Pronaf Agroecologia, implementado no ano de 2003.

Quanto à contribuição do Pronaf, enquanto política pública, há pesquisas que apontam para resultados positivos e outros que indicam problemas quanto à efetividade dos benefícios para os agricultores familiares. Estudos como os de Fernandes (2013) e Belik (2015) identificaram fatores positivos em relação ao Pronaf, sendo esses: reconhecimento da categoria agricultor familiar, instrumento para aumento da produção, ampliação de áreas plantadas, aumento da mecanização e modernização do sistema produtivo. Já os estudos de Weid (2006); Costa (2013) e Passos (2014) identificaram problemas relacionados ao Programa, evidenciando que o desenho institucional da política pública está em descompasso com o desenvolvimento rural sustentável. Dentre as críticas destacam-se: que o Pronaf incentiva o monocultivo; favorece culturas com uso intensivo de insumos químicos; direciona a produção para atividades específicas; reduz a diversidade nos sistemas produtivos; apoia a produção mercantil; promove a especialização produtiva dos agricultores; concentra a destinação dos recursos para agricultores mais capitalizados; exclui agricultores que não possuem os requisitos para acessar o crédito nas instituições financeiras; promove endividamento devido aos riscos inerentes ao mercado, etc.

Assim, considerando aspectos positivos e negativos apontados por estudos anteriores, a medida em que as contradições começam a ser identificadas, nota-se que o Pronaf pode não estar atendendo as reais necessidades da agricultura familiar, mas 
sim contribuindo para ampliação de disparidades. $\mathrm{O}$ artigo aqui apresentado apresenta aspectos relacionados aos limites hoje enfrentados pelos agricultores familiares que atuam na produção orgânica e agroecológica na região pesquisada e como o acesso a recursos financeiros poderiam potencializar as suas condições de desenvolvimento.

A agroecologia e a produção orgânica contribuem na promoção do desenvolvimento rural sustentável para a agricultura familiar, tendo em vista que objetivam pensar/realizar a produção de alimentos de forma diferenciada permitindo a produção rentável em menores escalas. A atividade agroecológica e orgânica têm como características diminuir ou eliminar a dependência da unidade de produção em relação aos insumos externos, valorizar o conhecimento prático dos agricultores, preservar o meio ambiente, proporcionar ganhos justos ao agricultor, considerando aspectos culturais, sociais, econômicos e ambientais (GLIESSMAN, 1998; ALTIERI, 2004; CAPORAL, 2009).

No Censo Agropecuário de 2006 foi apontado que havia no Brasil 90.498 estabelecimentos que faziam uso de agricultura orgânica, sendo que 5,6\% (5.106) destes eram certificados por entidades credenciadas. No Estado do Paraná, naquele ano, eram 7.528 estabelecimentos desenvolvendo agricultura orgânica, sendo que 12,1\% (909) destes estabelecimentos estavam certificados por entidades credenciadas (IBGE, 2020). Cabe destacar que o Censo Agropecuário de 2017 não apresentou informações sobre a produção orgânica e por este motivo os dados mais recentes, utilizados neste artigo, são os do MAPA (2020) que apontam, em junho de 2020, a existência no Brasil de 20.916 produtores orgânicos certificados, número que no Estado do Paraná corresponde a 3.631 produtores.

Já nos municípios pertencentes ao Território da Cidadania Cantuquiriguaçu estão certificados 243 produtores orgânicos (em 11 dos 20 municípios há produtores orgânicos), o que corresponde a 6,7\% dos produtores orgânicos certificados no Estado do Paraná. Nesta região o Movimento dos Trabalhadores Sem Terra tem importante papel no estímulo à agroecologia, uma de suas bandeiras, em uma realidade na qual há cinquenta assentamentos, com 4.400 famílias, o que corresponde a 15.817 pessoas, ou seja, 6,58\% da população da região (KRAJEVSKI, 2018).

No contexto da agricultura familiar, das políticas públicas voltadas a esta categoria, do crescimento da produção orgânica/agroecológica no país e no Estado do Paraná, o objetivo desta pesquisa consistiu em analisar em que medida o Pronaf Agroecologia vem estimulando a produção agroecológica na agricultura familiar do Território da Cidadania Cantuquiriguaçu. Os resultados obtidos apontam os limites e as potencialidades do acesso aos recursos do subprograma.

Para dar conta da abordagem o artigo está organizado estruturalmente em seis seções, incluindo esta introdução. A segunda, apresenta revisão bibliográfica acerca do desenvolvimento rural sustentável e da agroecologia e aspectos relacionados ao acesso ao Pronaf Agroecologia. A terceira parte trata de elementos referentes aos aspectos metodológicos, detalhando a forma como a pesquisa foi construída. Na quarta seção são apresentados os resultados e discussões da pesquisa e por fim constam as conclusões e as referências bibliográficas utilizadas na elaboração do artigo.

\section{REVISÃO DE LITERATURA}

Nesta seção são apresentadas abordagens sobre o desenvolvimento rural sustentável e a agroecologia na primeira subseção. Na segunda constam informações sobre o Programa Nacional de Fortalecimento da Agricultura Familiar como uma política que contribui para a promoção do desenvolvimento rural, com destaque para o subprograma direcionado para o estímulo à agroecologia e produção orgânica. 


\subsection{DESENVOLVIMENTO RURAL SUSTENTÁVEL E AGROECOLOGIA}

O conceito de desenvolvimento tem perspectivas diversas inclusive nas abordagens teóricas. Quanto ao desenvolvimento rural, Sevilla Guzmán (2005) identifica três categorias históricas do conceito, sendo elas o desenvolvimento comunitário, desenvolvimento rural integrado e o desenvolvimento rural sustentável. O desenvolvimento comunitário tem origem norte-americana, trata-se da reestruturação de mecanismos para introduzir os camponeses a uma nova agricultura relacionada ao mercado, na qual a condução dos recursos naturais torna-se um negócio. Os esforços para garantir o sucesso desse modelo, centraram-se na introdução de uma sociedade científica no campo, objetivando superar o atraso, sendo a Revolução Verde o meio de difusão desse modelo. O desenvolvimento rural integrado seguiu com as mesmas ambições do desenvolvimento comunitário, mas incorporou estratégias para melhorar o nível de vida da população rural, através de infraestruturas, apoio à saúde, garantindo e fortalecendo a ideia inicial de uma agricultura cada vez mais dependente do mercado.

O desenvolvimento rural sustentável (DRS) é uma concepção mais recente. Favaretto (2007), Schneider (2004) e Ribeiro (2015), conceituam como algo relacionado ao processo produtivo, mas que além disso, contempla aspectos sociais, ambientais, econômicos, culturais, político-institucionais, que objetivam a promoção do bem-estar da população rural. Na perspectiva social, prevê autonomia das comunidades com participação ativa da população rural nas questões que lhes cabem. Além disso, uma nova maneira de consumir, um olhar diferenciado para o processo produtivo, novas formas produtivas e de organização social também fazem parte dessa concepção. Do ponto de vista ambiental, exige ações voltadas ao benefício de todos os elementos do ecossistema, garantindo a produtividade e continuidade do sistema para futuras gerações. No sentido econômico, prevê o retorno financeiro e a distribuição equânime de renda. E na perspectiva político-institucional, pressupõe distribuição de terra e promoção de uma concorrência justa no mercado.

Exemplificando esta heterogeneidade de concepções acerca do desenvolvimento rural sustentável, pode-se recorrer às contribuições de Casado, Molina e Guzmán (2000). Os autores compreendem desenvolvimento rural sustentável a partir da agroecologia, na perspectiva de construção de um processo com base na identidade local, construído de forma participativa, objetivando transformações socioeconômicas, ambientais, garantindo o bem-estar das populações rurais. Esta percepção relaciona-se com a economia ecológica, que compreende o sistema econômico como algo que está dentro de um sistema maior, no caso o sistema ecológico.

A agroecologia se propõe a evitar a deterioração dos recursos naturais, portanto, necessita ir além do processo produtivo, introduzindo-se nos processos de circulação, modificando os mecanismos de exploração social (evitando assim a danificação causada à sociedade nas transações mediadas pelo valor de troca) (SEVILLA GÚZMAN, 2005). Casado, Molina e Guzmán (2000) percebem na agroecologia, a maneira de se alcançar o desenvolvimento rural sustentável e de enfrentar o atual modelo agrícola hegemônico, uma vez que as dimensões tratadas por ambos os temas são as mesmas. A agroecologia é multidimensional, uma vez que não pretende atender apenas a aspectos técnicos do processo produtivo, mas considera elementos culturais, econômicos, sociais, políticos, éticos, ambientais e, devido a todos estes elementos ela é considerada complexa. A partir dessas dimensões nota-se a similaridade de seu conceito com o que se almeja por meio do desenvolvimento rural sustentável. 
Existem diversos desafios na construção de agroecossistemas agroecológicos, que vão desde a desconstrução de algumas visões até elementos técnicos do processo produtivo convencional para agroecológico. Gliessman (2005), destaca níveis de transição dos processos produtivos: o primeiro, pressupõe o aumento da eficiência e eficácia das práticas convencionais, visando a redução de insumos externos caros, escassos e prejudiciais ao meio ambiente. No segundo nível, trocam-se as técnicas e insumos convencionais externos por métodos alternativos e insumos locais. No terceiro nível, são incorporados o novo conjunto de práticas e processos redesenhando o agroecossistema. Os níveis de transição agroecológica definidos por Gliessman, fornecem importante referencial de análise para técnicos e agricultores e permitem compreender que há processos produtivos nos quais são produzidos alimentos orgânicos, enquanto situações mais avançadas representam sistemas de produção agroecológicos. Apesar disso, a prática do processo de transição é complexa e não acontece de forma estática (ZUGASTI, 2009). Por este motivo é difícil caracterizar na prática, o nível de transição para a agroecologia de unidades de produção, tendo em vista que o processo ocorre de forma dinâmica e é composto de diferentes particularidades, conforme a realidade de cada unidade de produção. Assim, em função dos diferentes estágios da transição na qual se encontram os produtores teremos, no foco deste estudo, tanto a produção orgânica quanto agroecológica.

A partir da compreensão apresentada da agroecologia, entende-se que esta responde aos principais problemas gerados pela agricultura convencional como agressão das práticas agrícolas ao meio ambiente, perda da biodiversidade, alto grau de desperdício, uso de insumos químicos. A agroecologia possibilita a continuidade de existência dos agricultores familiares, por preservar ecossistemas, respeitar culturas alimentares, promover a soberania e segurança alimentar nutricional. Os movimentos sociais do campo têm ação importante na luta em defesa da agroecologia, sendo protagonistas neste processo. A ação do Estado também é fundamental para seu fortalecimento e consolidação. Entretanto, majoritariamente, o Estado brasileiro tem atuado no sentido de subsidiar o modelo hegemônico de desenvolvimento, pautado nos resultados da Revolução Verde.

É recente a inserção de políticas públicas para a agricultura familiar, apesar da representatividade da categoria a nível nacional, estadual e regional. A instituição do Pronaf, ainda que com algumas limitações, marca o início do reconhecimento pelo Estado da categoria de agricultores familiares, como será apresentado a seguir.

\subsection{PROGRAMA NACIONAL DE FORTALECIMENTO DA AGRICULTURA FAMILIAR}

Em 1995, é criado o Programa Nacional de Fortalecimento da Agricultura Familiar (Pronaf), constituído para amparar financeiramente as atividades agropecuárias e não agropecuárias, com a finalidade de aumentar a capacidade produtiva, contribuir para a melhoria na renda e geração de empregos através de crédito rural (BRASIL, 2019). A criação dessa política pública, representa o reconhecimento da categoria de agricultor familiar, que até então recebia denominações como pequenos produtores, produtores de baixa renda, agricultores de subsistência ou produtores familiares (SCHNEIDER, 2006).

Ao longo dos mais de vinte anos de existência do Pronaf, diferentes subprogramas foram criados, dentre eles, o Pronaf Agroecologia em 2003. Este subprograma busca disponibilizar crédito para agricultores em processo de transição ou já certificados na agroecologia. Dentre as finalidades de uso, o recurso pode ser destinado para construção, reforma ou ampliação de benfeitorias e instalações 
permanentes, aquisição de máquinas, equipamentos, instalação de sistema de irrigação e implementos agropecuários (MCR, 2019).

Os dados do Banco Central, sobre número de contratos e valores acessados, indicam que o Pronaf Agroecologia, no período de 2005 a 2018, representa menos de $1 \%$ dos recursos acessados via Pronaf sendo a linha que possui o menor acesso pelos agricultores. Na região Nordeste do Brasil, considerando as safras 2015/2016 e 2017/2018, foi acessado o maior número de contratos do subprograma, respondendo por $68,77 \%$ do total de contratos a nível nacional, somados os investimentos agrícolas e pecuários. Já a região Sul, é a que detém a maior parte dos montantes acessados, representando 48,9\% do montante total no período considerado (BACEN, 2019).

Dentre as finalidades de acesso dos recursos do Pronaf Agroecologia a nível nacional, estão a aquisição de tratores, máquinas e equipamentos, correspondendo a 29,87\% dos valores repassados até a safra 2017/2018. Do total de repasses, $23,31 \%$ correspondem à aquisição de veículos, principalmente caminhões e camionetes. Os demais recursos, são utilizados para custear a formação de culturas perenes de abacate, acerola, amora, café, caju, caqui, coco, coco-da-baía, florestamento e reflorestamento, goiaba, graviola, limão, mandioca, maracujá, morango, noz, mirtilo, pimenta-do-reino, tangerina, urucum. Destaque para as culturas de banana, cana de açúcar, laranja, uva que possuem o maior número de contratos e/ou valor repassado, nessa modalidade desde a instituição até a safra 2017/2018 (BACEN, 2019).

Em relação aos acessos de recursos no Estado do Paraná, no período desde a safra 2015/2016 até a safra 2017/2018 foram repassados $\mathrm{R} \$ 1.152 .572,45$, pela linha Pronaf Agroecologia, distribuídos em 23 contratos. Número pouco expressivo se comparado à linha de maior acesso, a do Pronaf Mais Alimentos, que no mesmo período repassou $\mathrm{R} \$ 2.896 .806 .723,75$, distribuídos em 73 mil contratos.

O crédito rural é um mecanismo importante para estimular e promover atividades produtivas, pois pode possibilitar a estruturação e custeio da manutenção da unidade de produção. Em função disso, consiste em instrumento importante para o desenvolvimento da agricultura familiar e do meio rural. Por outro lado, se aplicado sem uma análise de viabilidade poderá gerar problemas ao agricultor, podendo refletir negativamente na sucessão, permanência, qualidade de vida no campo. Por isso, é importante compreender as limitações e potencialidades geradas pelo Pronaf e o acesso às suas linhas, para entender que tipo de desenvolvimento esta política pública tem fomentado e que resultados gera para os agricultores familiares envolvidos com a produção agroecológica. Diante disso, na próxima seção, estão descritos os métodos utilizados para o desenvolvimento da pesquisa e obtenção dos resultados.

\section{METODOLOGIA}

Os objetivos da pesquisa caracterizam-se como descritivos e explicativos. A partir dessa combinação torna-se possível a identificação de fatores e seu posterior detalhamento e explicação, para assim descrever e analisar as limitações e potencialidades do Pronaf em relação ao estímulo à produção agroecológica na agricultura familiar em municípios da região do Território da Cidadania Cantuquiriguaçu ${ }^{1}$. A pesquisa buscou informações com a população pesquisada, para o levantamento de dados primários. A abordagem do problema se deu predominantemente pelo método qualitativo, considerando que este tipo de pesquisa

\footnotetext{
${ }^{1}$ Esta região foi constituída em 2008 a partir do Programa Territórios da Cidadania, instituído pelo Governo Federal com o objetivo de superar a pobreza e gerar trabalho e renda no meio rural.
} 
tem como objetivo conhecer mais detalhadamente os sujeitos pesquisados, sem que a preocupação seja com a representatividade da amostra.

O critério de seleção dos sujeitos pesquisados foi do tipo não probabilístico. Os entrevistados foram escolhidos, por conveniência, conforme a tipificação definida pela pesquisadora. Para chegar até os pesquisados, foi realizado contato com colaboradores da Rede Ecovida e CEAGRO - Centro de Desenvolvimento Sustentável e Capacitação em Agroecologia, entidades que atuam como agentes promotores da agroecologia e da cooperação no Território Cantuquiriguaçu.

Do total de produtores certificados conforme MAPA (2020), 51\% o são pela Associação Ecovida de Certificação Participativa (ou Rede Ecovida) e o Ceagro atua no apoio e capacitação dos agricultores para a agroecologia. Assim, a partir das entidades supracitadas, foi possível a participação em reuniões de grupos de agricultores com certificação. Nessa oportunidade foram apresentados os objetivos da pesquisa e foi realizada a troca de contatos com os agricultores familiares interessados em respondêla. Do total de contatos foi possível constituir uma amostra composta por 31 unidades produtivas, distribuídas em três categorias de agricultores familiares conforme caracterização apresentada no Quadro 1.

Os dados primários levantados nesta pesquisa, foram obtidos por meio de entrevista semiestruturada aplicada aos agricultores familiares selecionados nos seguintes municípios: Laranjeiras do Sul, Rio Bonito do Iguaçu, Nova Laranjeiras, Quedas do Iguaçu e Reserva do Iguaçu. Cabe destacar que nestes cinco municípios, conforme IBGE (2020), há 8.632 (85,2\% do total) estabelecimentos agropecuários pertencentes à agricultura familiar produzindo em uma área de 117.784 hectares (37,7\% do total). Conforme dados do MAPA (2020), nestes cinco municípios há 164 produtores certificados na produção orgânica/agroecológica.

Quadro 1 - Caracterização da amostra da pesquisa selecionada em municípios do Território da Cidadania da Cantuquiriguaçu, no ano de 2019.

\begin{tabular}{|l|l|c|}
\hline \multicolumn{1}{|c|}{ Tipo } & \multicolumn{1}{|c|}{ Características } & \multicolumn{1}{|c|}{$\begin{array}{c}\mathbf{N}^{\circ} \text { de } \\
\text { unidades } \\
\text { pesquisadas }\end{array}$} \\
\hline $\begin{array}{l}\text { Agricultores familiares } \\
\text { certificados (categoria A) }\end{array}$ & $\begin{array}{l}\text { Compreendem os agricultores familiares que } \\
\text { possuem certificação orgânica/agroecológica para } \\
100 \% \text { das culturas produzidas na propriedade. }\end{array}$ & 10 \\
\hline $\begin{array}{l}\text { Agricultores familiares com que produzem } \\
\text { produção concomitante de } \\
\text { agroecológicos e outros tipos de } \\
\text { produção (categoria B) }\end{array}$ & $\begin{array}{l}\text { Agricultores } \\
\text { orgânicos/agroecológicos (certificados) e que ainda } \\
\text { mantém a produção de culturas convencionais }\end{array}$ & 16 \\
\hline $\begin{array}{l}\text { Agricultores familiares que } \\
\text { estão em processo de transição } \\
\text { para Agroecologia } \\
\text { (categoria C) }\end{array}$ & $\begin{array}{l}\text { Trata-se dos agricultores familiares que ainda não } \\
\text { possuem certificação orgânica/ agroecológica, mas } \\
\text { que já iniciaram a adoção de práticas orgânicas, em } \\
\text { pelo menos parte da área da unidade de produção. }\end{array}$ & 6 \\
\hline
\end{tabular}

Fonte: Elaborado pelas autoras, 2018.

As duas primeiras categorias, do quadro 1, contém agricultores com certificação de produtos orgânicos do MAPA (2020), correspondendo a 15,85\% daqueles existentes no cadastro mencionado. Em relação ao terceiro tipo não há informações estatísticas que indiquem quantos agricultores familiares na região encontram-se em transição, o que impede a indicação de representatividade do grupo diante do universo existente.

As entrevistas nas 31 unidades produtivas foram organizadas sob forma de roteiro buscando obter informações sobre as famílias e propriedades. A pesquisa procurou compreender a problemática de acesso ao crédito via Pronaf sob o ponto de 
vista do agricultor familiar. O entrevistado não precisou se identificar, tendo preservado o anonimato.

Cabe ressaltar que o critério utilizado para a escolha da amostra não permite a generalização dos resultados. Sendo assim, esta pesquisa é explicativa e válida para o grupo de agricultores que concederam a entrevista, apesar de haver a expectativa de que a análise isolada contribua com o todo. Assim, os resultados obtidos são apresentados e discutidos na próxima seção.

\section{RESULTADOS E DISCUSSÃO}

Conforme mencionado na seção da metodologia, três grupos de agricultores familiares formaram a amostra desta pesquisa, totalizando 31 unidades de produção pesquisadas, conforme caracterização efetuada no quadro 1 . O planejamento inicial previa entrevistar famílias de dez unidades produtivas em cada categoria, entretanto constatou-se que há maior número de agricultores que pertencem à categoria $\mathrm{B}$ e foram enfrentadas dificuldades para localizar agricultores na categoria $\mathrm{C}$.

$\mathrm{Na}$ categoria A, em que $100 \%$ das culturas são certificadas como produção orgânica/agroecológica, foram efetuadas entrevistas em 10 unidades de produção, nas quais participaram 16 pessoas com idade superior a 18 anos, sendo que a idade média dos entrevistados foi de 41 anos. Na categoria B parte das culturas desenvolvidas possui certificação orgânica/agroecológica. Nestas 15 unidades de produção participaram 21 pessoas com idade superior a 18 anos e idade média de 47 anos. A categoria $\mathrm{C}$ é composta por agricultores familiares em transição para a agroecologia, sendo estas as unidades de produção que ainda não possuem certificação orgânica/agroecológica. Nas 6 unidades de produção pesquisadas participaram 7 pessoas, cuja idade média é de 36 anos.

Nesta última categoria houve a maior dificuldade de localizar agricultores, tendo em vista que a Rede Ecovida e o Ceagro ainda não dispõem do cadastramento destes agricultores, uma vez que estes apresentam descontinuidade em suas tentativas de transição para a agroecologia. Santos (2016) comenta sobre as dificuldades do processo de transição, o qual é desafiador, devido aos problemas com fertilidade, disponibilidade de água, manejo de plantas espontâneas e insetos, manutenção da sanidade animal, ausência de recursos financeiros para viabilização e problema de dívidas no período anterior; além da pressão social e política para manutenção dentro do modelo hegemônico. Isso denota a necessidade de um maior acompanhamento técnico das famílias que se propõem a fazer a transição, ou seja, um conjunto de políticas que incluem ações de pesquisa e extensão rural, por exemplo, o que extrapola o escopo do Pronaf Agroecologia.

Todos os entrevistados na pesquisa (44 pessoas no total) são filhos de agricultores, sendo que alguns, por necessidade, precisaram sair do campo e desenvolver atividades não rurais, para mais tarde retornar ao campo. Estes que manifestaram ter residido algum tempo no meio urbano atuaram como professor(a), pedreiro, mecânico, representante de organização coletiva e empregada doméstica. Atualmente, constata-se que $31 \%$ dos entrevistados atuam concomitantemente na propriedade e fora dela. Dentre os trabalhos, que hoje são desenvolvidos fora da propriedade foram mencionados: assessoria técnica em cooperativa, técnico agrícola, feirante, confeiteira.

No quesito escolaridade, metade dos respondentes cursou apenas as séries iniciais do ensino fundamental. Os motivos apontados para a descontinuidade dos estudos foram: a falta de condições socioeconômicas, a distância em relação à escola, pai ou responsável não permitiu continuar os estudos e preferência do entrevistado por 
trabalhar ao invés de estudar. Dentre os demais, 31,3\% dos entrevistados conseguiu concluir o ensino médio e destes, $18,8 \%$ ingressaram no ensino superior. De modo geral, os entrevistados enfatizaram a importância de estudar como sendo um elemento de ampliação de capacidades e emancipação do indivíduo.

Como forma de obter melhores condições de acesso às políticas públicas, fomentar a comercialização de seus produtos, acessar serviços à comunidade é comum que os agricultores familiares se organizem e se vinculem em associações e cooperativas. Em relação à participação dos entrevistados em organizações coletivas, observou-se que todos possuem vínculo com pelo menos uma organização. Dos agricultores da categoria A e B, todos possuem certificação pela Rede Ecovida. Esta, funciona por meio da organização das famílias em grupos informais, associações ou cooperativas, e concede certificação participativa aos agricultores vinculados.

Os entrevistados também mencionaram a participação como associados de cooperativas de crédito nas quais há maiores possibilidades de acesso a empréstimos e financiamentos, além de produtos e serviços bancários. Alguns participam de cooperativas de produção, nas quais há fomento à comercialização e beneficiamento dos produtos. Foram ainda mencionadas a participação em associações de produtores, as quais objetivam oportunizar parcerias com entidades públicas/ privadas para capacitação aos agricultores, além de participar de licitações para uso de maquinários, por exemplo.

A diversidade produtiva é um elemento ímpar na produção agroecológica, característica confirmada nas pesquisas, uma vez que são produzidas hortaliças, mandioca, amendoim, girassol, abóbora, arroz, milho, feijão, frutas, plantas medicinais. No caso das unidades que estão em transição para a agroecologia, a horta ainda está em desenvolvimento, e existe representatividade significativa no monocultivo de milho ou atividade leiteira, as quais ocupam maior parte da área, uma vez que tais atividades são desenvolvidas no modo convencional. Essas podem contribuir na dependência de insumos externos da unidade de produção, pois tanto no plantio de milho convencional quanto na produção de leite, os agricultores acabam por ficar dependentes do mercado, seja em relação à demanda, seja em relação aos preços. Apesar disso, a renda proveniente destas atividades, sobretudo no caso dos agricultores que estão em transição, é significativa, haja vista, que ainda não iniciaram a comercialização de produtos agroecológicos.

Sobre o primeiro contato com a agroecologia, $75 \%$ dos entrevistados responderam ter acontecido em reuniões e eventos do Movimento dos Trabalhadores Sem Terra (MST), o qual tem como uma das bandeiras a adoção da agroecologia. Cabe destacar que a maior parte dos entrevistados tem vínculo com movimentos sociais, fato evidenciado por muitos como fator significativo na escolha da produção agroecológica. Também foram apontados como elementos que contribuíram para escolha da produção agroecológica: saúde $(81,3 \%)$, melhor qualidade de vida $(56,3 \%)$, apoio do CEAGRO (56,3\%), produzir bens com maior qualidade $(18,8 \%)$.

Em relação às principais dificuldades que enfrentaram no processo de transição para a agroecologia, os agricultores destacam a incidência de pragas e doenças nas plantas, que segundo os entrevistados, ocorre com mais intensidade no início da transição. Além das pragas, a dificuldade na comercialização também foi um elemento identificado como limitador. Na categoria A um dos entrevistados mencionou que "De nada adianta produzir, se não tem pra quem vender. A gente sabe que tem bastante mercado pra fora (Curitiba, São Paulo) que pagam mais. Mas se não tem o contato com esse povo, e formas de levar os produtos até eles, fica difícil”. Para conseguir acesso ao mercado consumidor os agricultores se vinculam a cooperativas/associações 
de produção, organizações que buscam comercializar produtos por meio de políticas públicas como o Programa Nacional de Alimentação Escolar (PNAE).

A falta de conhecimento técnico e das formas de manejo mais adequadas, também foram elementos relatados pelos entrevistados como sendo desafios, na fase da transição. Os agricultores mencionaram que na agroecologia o aprendizado é diário, pois frequentemente se deparam com descobertas que surgem após experiências mal sucedidas. Além das limitações mencionadas anteriormente, a falta de recursos financeiros também foi um dos elementos apontados como dificultadores no processo de transição.

Sobre as dificuldades do processo de transição para a agroecologia, Santos (2016) destacou como elementos dificultadores: problemas com fertilidade, disponibilidade de água, manejo de plantas espontâneas e insetos, manutenção da sanidade animal, ausência de recursos financeiros para viabilização e problema de dívidas no período anterior; além da pressão social e política para manutenção dentro do modelo hegemônico; problemas econômicos pela ruptura; dificuldades na comercialização.

Apesar das dificuldades enfrentadas todos os pesquisados relataram interesse pela continuidade na produção agroecológica. Há relatos de orgulho pelos avanços que obtiveram e por construir uma produção na qual o foco não é a quantidade, mas sim a qualidade dos alimentos.

Em relação aos dados de acesso ao crédito rural, foi possível observar que $71 \%$ dos agricultores entrevistados já acessou o Pronaf pelo menos uma vez. A categoria B, apresentou o maior número de entrevistados com acesso ao Pronaf. E o grupo com menor acesso, são os agricultores da categoria $\mathrm{A}$, havendo número significativo de entrevistados que nunca acessou o Pronaf por dificuldades como as restrições legais para acesso a tal recurso, tendo em vista que vários destes agricultores estão ainda na condição de acampados, situação na qual ainda não possuem a documentação exigida pelas instituições financeiras para acessar o crédito.

Dentre aqueles que já acessaram recursos via Pronaf, os recursos acessados foram nas modalidades Pronaf Custeio Agrícola, Pronaf Custeio Pecuário e Pronaf Investimento Mais Alimentos. Estes foram utilizados para custear e investir em atividades convencionais (apesar de muitos já estarem desenvolvendo a atividade agroecológica quando acessaram o recurso). No custeio, destacam-se as finalidades de plantio de soja, milho, trigo e feijão e para manutenção de animais. E na linha Investimento foram efetuadas a aquisição de matrizes leiteiras, tanque resfriador, ordenhadeira, sistema de irrigação, veículo utilitário, correção do solo, destoca e forrageira.

Para ter acesso ao Pronaf, os agricultores necessitam estar ativos na Declaração de Aptidão ao programa e possuir um projeto, no qual estão descritos a viabilidade e a alocação dos recursos, para o qual contam com o apoio de técnicos e engenheiros agrônomos. Cabe enfatizar que a assistência técnica é um elemento ímpar no quesito crédito rural, tendo em vista a complexidade de informações a serem consideradas na realização de um projeto de investimento ou custeio (agrícola ou pecuário), pois são operações que exigem conhecimento, orientação, coordenação, avaliação, planejamento e acompanhamento por profissionais habilitados. A falta de assistência técnica ou a baixa qualidade da prestação deste serviço são fatores que podem influenciar negativamente na geração de renda por parte daqueles que acessam o crédito (GUANZIROLI, 2007).

Os agricultores entrevistados que acessaram o Pronaf, seja na linha de custeio ou de investimento, receberam assistência técnica de profissionais com formação técnica em agropecuária ou graduação em engenharia agronômica. Observou-se que 
os agricultores contrataram o profissional com recursos próprios para elaboração do projeto e posteriormente (após a liberação do recurso e aquisição do objeto financiado ou do plantio) o mesmo técnico fez laudo de acompanhamento e fiscalização da aplicação do recurso.

Dentre as observações efetuadas nas entrevistas uma delas diz respeito à existência de situações em que os recursos do Pronaf são aplicados para além das finalidades amparadas pelas regras. Ou seja, houve relatos em que o recurso solicitado era para financiamento de vacas, mas o dinheiro foi aplicado para efetuar cirurgia de um filho; outro caso em que o recurso solicitado era para comprar vacas mas a aplicação foi para a compra de um lote de terras; mas houve também quem relatasse ter utilizado parte dos recursos para atender a atividade agroecológica, ainda que no projeto a alocação não estivesse prevista.

Outra constatação observada foi a existência de número significativo de entrevistados que enfrentou problemas no pagamento das prestações, por fatores relacionados às garantias e frustrações de safra. Tais problemas levaram estes agricultores a não acessar novos financiamentos em instituições financeiras. A solução mencionada foi de que passaram a adquirir os insumos diretamente em cooperativas de grãos com pagamento até a colheita e juros mais elevados se comparados aos do Pronaf.

A fim de identificar a necessidade de recursos financeiros externos na unidade de produção, os agricultores foram motivados a avaliar sua situação. Foram questionados sobre a autonomia financeira do estabelecimento (para os casos que não dependem de empréstimos e financiamentos); se este apresenta dependência relativa de recursos financeiros externos (pressupondo a necessidade ocasional ou pontual de empréstimos e financiamentos) ou tem dependência permanente de recursos financeiros externos (para os casos que dependem de empréstimos e financiamentos para garantir a produção na unidade).

Nos três grupos o maior percentual de agricultores respondeu que tem dependência relativa de recursos financeiros externos. No grupo B este percentual é de $86,6 \%$, no $\mathrm{C}$ de $83 \%$ e no $\mathrm{A}$ de $60 \%$. Quanto àqueles que afirmaram terem autonomia financeira, no grupo A 10\% apontou ser esta a situação, no grupo B foram $6,7 \%$ e no C nenhum agricultor afirmou ter esta independência. Por fim, chama a atenção a categoria A e a categoria $\mathrm{C}$, que tiveram 30\% e 17\% respectivamente, dos respondentes com dependência permanente. Todos os entrevistados consideram que a fase da transição para a agroecologia é aquela que mais demanda recursos financeiros externos.

Foi observado, dentre os respondentes, cautela com relação ao acesso a novos créditos, fato que pode ter relação com as experiências negativas que tiveram, tais como terem ficado inadimplentes, juros acrescidos de contratos renegociados, pouca orientação técnica, atraso de parcela. A categoria $\mathrm{C}$, foi aquela em que as falas dos agricultores apontaram para uma quantidade maior de benefícios obtidos através do acesso ao Pronaf. Dentre os benefícios mencionados foram citados: as baixas taxas de juros e os prazos para pagamento.

Ao serem questionados sobre o conhecimento que possuem acerca do Pronaf Agroecologia, todos os entrevistados demonstraram que possuem pouco conhecimento em relação às características da linha em questão. Assim, o fato de não acessarem esta linha é motivado pelo desconhecimento ou porque não visualizam vantagens em relação às demais linhas, tendo em vista que, segundo eles, as exigências são maiores e os benefícios são os mesmos do crédito comum. Conforme mencionado por um dos entrevistados, no sistema agroecológico a demanda por insumos é menor se comparada ao pacote para plantio de soja, milho, trigo e outros monocultivos, 
elemento que também foi apontado por Gliessman (1998), Altieri (2004) e Caporal (2009) em suas publicações.

A partir das entrevistas é possível observar que o Pronaf tem contribuído pouco para com a agroecologia na região pesquisada. Em consonância com resultados apontados por Schneider (2006) e Costa (2013) é possível constatar que o Pronaf, favorece mais ao aumento no grau de especialização das atividades agrícolas. Avaliase que a existência de uma linha de crédito específica para a Agroecologia, é apenas um elemento isolado, sobre a qual a maioria dos beneficiários possui poucos conhecimentos.

Cabe ressaltar outras dificuldades mencionadas pelos entrevistados, tais como condições das estradas, que por sua vez prejudicam a logística e o transporte dos produtos. A comercialização também foi identificada como limitador, pois como apontado pelos entrevistados, não adianta produzir sem um mercado para o qual escoar a produção. Aliado a isso a dependência de comercialização por meio de programas como o PNAE também se mostrou um elemento de vulnerabilidade. Essas questões extrapolam o escopo do Pronaf, apontando para a necessidade de um conjunto de políticas púbicas de fomento à agroecologia.

\section{CONCLUSÃO}

Este estudo buscou analisar em que medida o Pronaf vem estimulando a produção agroecológica na agricultura familiar, em municípios do Território da Cidadania Cantuquiriguaçu. Em relação ao subprograma foram observadas as condições de acesso a este tipo de crédito por parte de produtores certificados e em transição para a agroecologia. Em seguida, foram descritas e analisadas as potencialidades e limitações do Pronaf no estímulo à produção agroecológica no referido Território, através do perfil e das experiências relacionadas ao acesso ao crédito do Pronaf dos entrevistados.

Em relação à análise das potencialidades e limitações do Pronaf no estímulo à produção agroecológica no espaço analisado foram observados diversos elementos. Dentre as limitações, está a falta de acesso à linha Pronaf Agroecologia, uma vez que para os agricultores pesquisados, há desconhecimento sobre pré-requisitos e características da linha. Além disso, destacam-se as frustrações com o Pronaf para atividades convencionais, problemas causados por atraso de parcela decorrentes de frustração de safra, problemas decorrentes das dificuldades de pagamento de parcela, baixo retorno a partir dos investimentos. Além dos elementos já mencionados, as dificuldades de enquadramento por falta de documentação são outro limitador para acesso à linha.

Ainda foi observado em alguns dos locais pesquisados um desamparo político. São observadas carências de infraestrutura de acesso às unidades de produção, em alguns casos tão graves que impossibilitam a chegada com veículo automotor. Logo, não basta o acesso à terra como política pública de desenvolvimento rural, é preciso que o agricultor tenha condições mínimas de moradia, saúde, educação, financeira e deslocamento para permanecer e sobreviver nessa terra.

O Pronaf representa um avanço nas políticas públicas para a agricultura familiar, assim como a criação da linha Agroecologia. Entretanto, ainda se fazem necessários avanços para uma maior proximidade da realidade dos agricultores familiares, pois a existência do Pronaf, ou da linha Agroecologia, por si só não garante que estes produtores tenham acesso ao crédito e consigam se desenvolver.

Ademais, os desafios também são observados no processo produtivo, e iniciam desde a construção de barreiras para isolar a unidade produtiva de agrotóxicos. Num 
desabafo, um dos agricultores entrevistados menciona "Veja bem se não é contraditório, é nóis que temos que construir a barreira, logo nóis que tamo contribuindo com a redução do veneno, com a preservação do rio, do solo, da saúde". Tendo em vista os inúmeros desafios enfrentados no processo produtivo e na comercialização, nota-se que do modo como funciona atualmente, o Pronaf não atende às necessidades da maioria dos pesquisados. A política pública de financiamento da produção é fundamental, é necessária, mas parece não ser suficiente para fazer com que a agroecologia avance.

E possível observar que o Pronaf, tem potencializado forças hegemônicas do mercado, podendo fragilizar no caso da agricultura familiar as estruturas sociais e produtivas. Assim, a existência destes recursos e os subprogramas como o da agroecologia são essenciais para que se possa iniciar um suporte aos agricultores familiares que atuam na produção agroecológica, entretanto, há necessidades de ajustes para dar conta das realidades existentes. Desta forma, constata-se que a partir da amostra observada, o subprograma não atende aos pressupostos do desenvolvimento rural sustentável, pois não é capaz de contemplar suas dimensões sociais, ambientais, econômicos, culturais, político-institucionais, dimensões estas, inerentes também à agroecologia, que buscam a promoção do bem-estar da população rural.

\section{REFERÊNCIAS}

ALTIERI, Miguel. Agroecologia: a dinâmica produtiva da agricultura sustentável. 4 ed. Porto Alegre: Editora da UFRGS, 2004.

BACEN, Banco Central do Brasil. Matriz de dados do crédito rural. Disponível em: <http://www.bcb.gov.br/en/\#!/c/MICRRURAL/> Acesso em: 10 fev. 2019.

BELIK, Walter. $O$ financiamento da agropecuária brasileira no período recente. Rio de Janeiro: IPEA, 2015. Disponível em:

<http://repositorio.ipea.gov.br/bitstream/11058/3407/1/td_2028.pdf > Acesso em: 19 jun. 2018.

BRASIL. Secretaria Especial de Agricultura Familiar e do Desenvolvimento Agrário. PRONAF. Disponível em: <http://www.mda.gov.br/sitemda/tags/pronaf > Acesso em: 9 fev. 2019.

CAPORAL, Francisco Roberto. Agroecologia: uma ciência do campo da complexidade. Gervásio Paulus- Brasília: 2009, 111 p.

CASADO, Gloria Guzmán I.; MOLINA, Manuel Navarro González de; GUZMAN, Eduardo Sevilla (coord.). Agroecologia y desarrollo rural sostenible. In: Introduccion a la agroecologia como desarrollo rural sostenible. Ediciones Mundi Prensa. 2000.

COSTA, Vibérica Gonçalves da. Políticas Públicas e Agricultura Familiar: Uma avaliação do PRONAF em dois assentamentos rurais da Mata Sul Paraibana. 2013. 140 f. Dissertação (Mestrado em Desenvolvimento e Meio Ambiente) Universidade Federal da Paraíba, João Pessoa, 2013. Disponível em:

<https://sucupira.capes.gov.br/sucupira/public/consultas/coleta/trabalhoConclusao /viewTrabalhoConclusao.jsf?popup=true\&id_trabalho=378946> Acesso em: 02 nov. 2017. 
FAVARETTO, Arilson da Silva. Paradigmas do Desenvolvimento Rural em Questão Do Agrário ao Territorial. 3 ed. São Paulo: Edusp, 2007. $296 p$.

FERNANDES, Alana Miguel Serafini. O Pronaf na Agricultura Familiar: sua criação, distribuição e principais resultados. 2013.Disponível em: <https://www.lume.ufrgs.br/bitstream/handle/10183/79225/000900902.pdf?seque nce $=>$ Acesso em: 20 de jun. 2018.

GLIESSMAN, Stephen R. Agroecology: the ecology of sustainable food systems. $2^{\mathrm{a}}$ Ed. CRC press, 1998.

Sustentável. 3 ed. Porto Alegre: Editora da UFRGS, 2005.

GUANZIROLI, Carlos Enrique. PRONAF dez anos depois: resultados e perspectivas para o desenvolvimento rural. Revista de Economia e Sociologia Rural. Rio de Janeiro, v. 45, n. 2, p. 301-328, abr./jun. 2007.

IBGE, Instituto Brasileiro de Geografia e Estatística. Censo Agropecuário 2017. Disponível em: < https://sidra.ibge.gov.br> Acesso em: jun. 2020.

INCRA, Instituto Nacional de Colonização e Reforma Agrária. Titulação. Disponível em: <http://www.incra.gov.br/titulacao> Acesso em: 22 jun. 2019.

KRAJEVSKI, Luis Claudio. A importância da UFFS/Campus Laranjeiras do Sul(PR) e o Desenvolvimento do Território Cantuquiriguaçu. Blumenau: Furb. Tese de Doutorado.2018, $434 \mathrm{p}$.

MAPA, Ministério da Agricultura Pecuária e Abastecimento. Cadastro Nacional de produtores Orgânicos. Disponível em: <https://www.gov.br/agricultura/ptbr/assuntos/sustentabilidade/organicos/cadastro-nacional-produtores-organicos $>$. Acesso em: 10 jun. 2020.

MCR. Manual do Crédito Rural. Atualização MCR nº 649, de 13 de junho de 2018. Disponível em: <https://www3.bcb.gov.br/mcr> Acesso em: 10 jun. 2019.

PASSOS, Ana Tereza Bittencourt. O impacto do PRONAF Sustentável sobre a sustentabilidade agrícola da agricultura familiar: o caso da microrregião do Vale do Médio Curu no Estado do Ceará. 2014. 211 f. Dissertação (Mestrado em Desenvolvimento e Meio Ambiente) Universidade Federal da Paraíba, João Pessoa, 2014. Disponível em: <http://www.repositorio.ufc.br/handle/riufc/14250 > Acesso em: 15 out. 2017.

RIBEIRO, Rita de Cássia. Desenvolvimento Rural Sustentável e Agricultura Familiar: Diagnóstico Participativo de Indicadores Econômicos, Sociais e Ambientais da Região Oeste do Paraná. 2015. 84 f. Dissertação (Mestrado em Desenvolvimento Rural Sustentável) Universidade Estadual do Oeste do Paraná, Marechal Cândido Rondon, 2015.

SANTOS, Cristina Sturmer dos. Análise do processo de transição agroecológica das famílias agricultoras do Núcleo da Rede Ecovida de Agroecologia Luta Camponesa. 2016. 196 f. Dissertação (Mestrado em Agroecologia e Desenvolvimento Rural Sustentável) Universidade Federal da Fronteira Sul (UFFS, PR), 2016.

SCHNEIDER, Sérgio. Teoria social, agricultura familiar e pluriatividade. Associação Nacional de Pós-Graduação e Pesquisa em Ciências Sociais, 2006.

SEVILla GUZMÁN, Eduardo. Agroecologia e Desenvolvimento Rural Sustentável. In: AQUINO, Adriana Maria de; ASSIS, Renato Linhares de. 
Agroecologia: princípios e técnicas para uma agricultura orgânica sustentável. Brasília: Embrapa Informação Tecnológica, 2005. Disponível em: <https://www.agencia.cnptia.embrapa.br/recursos/AgrobCap4ID1B89GAobdo.pdf > Acesso em: 24 fev. 2019.

WEID, Jean Marc von der. A transição agroecológica das políticas de crédito voltadas para a agricultura familiar. Agriculturas - v. 3 - no 1 - abril de 2006. Disponível em: <http://aspta.org.br/wp-content/uploads/2014/10/Artigo-5-A-transiçãoagroecológica-das-políticas-de-crédito-voltadas-para-a-agricultura-familiar.pdf> Acesso em: 07. out 2017.

ZUGASTI, Carlos Guadamarra. Agroecologia e desarollo rural em Mexico: bases agroecológicas, sistemas sostenibles y soberania alimentaria. In: SAUER, Sergio; BALESTRO, Moisés Villamil. (org.). Agroecologia e os desafios da transição agroecológica. São Paulo: Expressão popular, 2009.

\section{Sobre o(s) Autor(es):}

\section{Grasieli de Fátima Rode}

Graduada em Ciências Econômicas pela Universidade Federal da Fronteira Sul (2015), Graduanda em Administração pelo Centro Universitário Internacional, Especialista em Planejamento e Gestão Estratégica, pelo Centro Universitário Internacional (2017). Mestranda no Curso de Pós Graduação em Agroecologia e Desenvolvimento Rural Sustentável, pela Universidade Federal da Fronteira Sul. Atualmente é Orientadora Educacional no Centro Universitário Internacional e Analista de Negócios na Cresol. ORCID: http://orcid.org/o0oo-0002-9113-878X. Email: grasielirode@gmail.com

\section{Janete Stoffel \\ Doutora em Desenvolvimento Regional pela Universidade de Santa Cruz do Sul/RS. Mestre em Políticas e Projetos de Desenvolvimento pela Universidade Regional do Noroeste do Estado do Rio Grande do Sul (2004). Graduada em Ciências Econômicas pela Universidade Regional do Noroeste do Estado do Rio Grande do Sul (1998) com especialização Lato Sensu em Comércio Exterior (2002). ORCID: http://orcid.org/o000-0003-0689-0414. Email: janete.stoffel@uffs.edu.br}

\footnotetext{
Anelise Graciele Rambo

Docente do Departamento Interdisciplinar da Universidade Federal do Rio Grande do Sul (UFRGS), do Programa de Pós-graduação em Dinâmicas Regionais e Desenvolvimento (PGDREDES/UFRGS) e do Programa de Pós-graduação em Agroecologia e Desenvolvimento Rural Sustentável da Universidade Federal da Fronteira Sul (UFFS). Possui Doutorado em Desenvolvimento Rural pela Universidade Federal do Rio Grande do Sul - PGDR/UFRGS (2011); Mestrado em Geografia também pela Universidade Federal do Rio Grande do Sul - UFRGS (2006) e Graduação em Geografia pela Universidade Regional do Noroeste do Estado do Rio Grande do Sul - UNIJUI (2003)

ORCID: http://orcid.org/oooo-0001-9974-9844 Email: ane_rambo@yahoo.com.br
} 